\title{
Ativismo e deficiência: um estudo sobre os repertórios que dão sentido à vida independente
}

Activism and disability: a study on the meanings of independent living

Activismo y deficiencia: un estudio sobre los repertorios que dan sentido a la vida independiente

\section{Mariana Prioli Cordeiro*}

\begin{abstract}
Resumo
Neste trabalho, buscou-se identificar os repertórios usados por ativistas do Movimento de Vida Independente para dar sentido à noção de vida independente. Para isso, foram analisados documentos de domínio público produzidos por esses ativistas, tais como livros, sítios de internet, livretos, material publicitário, jornais institucionais, etc., bem como foram realizados grupos focais com alguns de seus membros. Essa análise permitiu constatar que os principais repertórios usados para dar sentido a essa noção são: independência, autonomia, empoderamento, autodeterminação, participação e igualdade de oportunidade. Permitiu, também, concluir que vida independente é entendida como práxis, ou seja, não há filosofia sem a prática de vida independente e vice-versa. $\mathrm{O}$ uso desses repertórios indica que os ativistas buscam ser reconhecidos como atores sociais, participar ativamente da sociedade e assumir o controle de suas vidas.
\end{abstract}

Palavras-chave: Movimento de Vida Independente; repertórios interpretativos; vida independente.

\begin{abstract}
The goal of this study was to identify the repertoires used by activists of the Independent Living Movement to convey the meaning of independent living. Documents of public domain produced by those activists, including books, websites, advertisement material and institutional papers, were reviewed, and two focal groups were created for analysis. The conclusion of the analysis identified the repertories used to convey the concept of independent living as independence, autonomy, empowerment, self-determination, participation and equal opportunity. Moreover, independent living was understood as praxis, in other words,
\end{abstract}

Texto recebido em março de 2009 e aprovado para publicação em setembro de 2009.

Doutoranda do Programa de Estudos Pós-graduados em Psicologia Social da Pontifícia Universidade Católica de São Paulo, bolsista do Conselho Nacional de Desenvolvimento Científico e Tecnológico - PUC SP, e-mail: mpriolicordeiro@ hotmail.com. 
as the process of transforming theoretical knowledge into practice. The use of those repertories indicates that the activists seek recognition as social actors, that is, they wish to be actively involved in society and control their own lives.

Key words: Independent Living Movement; Interpretative repertoire; Independent living

\section{Resumen}

En este trabajo, se ha tratado de identificar los repertorios que los activistas del Movimiento de Vida Independiente utilizan para dar sentido a la noción de vida independiente. Para eso, fueron analizados documentos de dominio público producidos por estos activistas, tales como libros, sitios de Internet, folletos, anuncios, periódicos institucionales etc., así como fueron realizados dos grupos focales con algunos de sus miembros. Este análisis ha permitido constatar que los principales repertorios utilizados para dar sentido a esta noción son: independencia, autonomía, empoderamiento, autodeterminación, participación e igualdad de oportunidades. Ha permitido, también, concluir que la vida independiente es entendida como praxis, o sea, no hay filosofía sin la práctica de la vida independiente y viceversa. El uso de estos repertorios indica que los activistas tratan de ser reconocidos como actores sociales, participar activamente en la sociedad y tomar el control de sus vidas.

Palabras clave: Movimiento de Vida Independiente; Repertorios interpretativos; Vida Independiente.

\section{Introdução}

0 s movimentos sociais em defesa das pessoas com deficiência ${ }^{1}$ têm assumido um papel cada vez mais importante na luta pela melhoria da qualidade de vida dessa população. Suas principais reivindicações são relacionadas à educação, ao trabalho, à saúde e aos serviços que implicam maior participação dessas pessoas em todos os momentos do convívio social (Neves, 2000). Este artigo aborda um desses movimentos, o Movimento de Vida Independente (MVI), sendo que, nessa abordagem, buscamos descrever e analisar os repertórios disponíveis para dar sentido à vida independente. Com isso, objetivamos, em primeiro lugar, “dar voz” às próprias pessoas com deficiência, já que essa é uma prática pouco comum em trabalhos acadêmicos (Nunes et al., 1998). Em segundo

\footnotetext{
De acordo com a sugestão de Amaral (1996), neste artigo, utilizaremos a terminologia "pessoa com deficiência", a fim de acentuar o caráter dinâmico e social da deficiência, deslocar o eixo do atributo do indivíduo para sua condição e destacar o "sujeito da frase", não colocando a pessoa como sinônimo da deficiência, ressaltando a unicidade do sujeito e sendo mais descritiva que valorativa.
} 
lugar, buscamos suprir uma lacuna na literatura sobre deficiência e movimentos sociais: a de trabalhos que abordam o MVI.

Afora o fato de esse movimento ser pouco estudado, nossa opção pelo MVI, entre os diversos movimentos pelos direitos das pessoas com deficiência existentes hoje no Brasil, deu-se por diversas razões: ele é um movimento de (e não para) pessoas com deficiência ${ }^{2}$ e é um grupo reivindicativo bastante ativo no Brasil e em vários outros países. Além disso, nas primeiras aproximações que fizemos com diversos grupos, antes de escolhermos um movimento específico, já identificávamos que o MVI se alinhava à perspectiva do modelo social da deficiência (que transfere a responsabilidade pelas desvantagens, comumente atribuída às limitaçôes corporais, para a incapacidade da sociedade de ajustar-se à diversidade) e propunha estratégias e serviços para implementar sua "filosofia". Essa dimensão de práxis na busca de uma inversão da lógica normativa ganhou, de fato, visibilidade em nossa pesquisa, reiterando nossa percepção inicial.

Este estudo poderia seguir múltiplos caminhos. Abordar as formas de organização do MVI seria um deles. Investigar o processo de formação de consciência política de seus ativistas, outro. No nosso caso, optamos por seguir o viés da produção de sentidos, já que, seguindo esse caminho, poderíamos entender como esses ativistas constroem os repertórios interpretativos com base nos quais compreendem e lidam com as situaçóes e fenômenos à sua volta (M. J. Spink \& Medrado, 1999). E, por conseguinte, entender como definem e vivenciam a vida independente.

Para seguirmos esse caminho, adotamos a perspectiva construcionista. Para esta, os sentidos não são produzidos por meio de uma atividade cognitiva intraindividual, tampouco por meio de uma simples reprodução de modelos determinados previamente, mas numa prática social dialógica baseada na linguagem. Sendo assim, a produção de sentidos é considerada um fenômeno sociolinguístico que tem como meta entender as práticas discursivas do cotidiano e os repertórios usados nessas produções discursivas (Spink \& Medrado, 1999).

Por práticas discursivas M. J. Spink e Medrado compreendem os "momentos de ressignificações, de rupturas, de produção de sentidos, ou seja, os momentos ativos do uso da linguagem, nos quais convivem tanto a ordem como a diversidade" (Spink \& Medrado, 1999, p. 45). Diante disso,

\footnotetext{
A distinção entre movimentos "de" e "para" pessoas com deficiência surgiu no início da década de 1980 para diferenciar os grupos reivindicativos criados e dirigidos majoritariamente por pessoas com deficiência dos grupos formados por familiares e profissionais da saúde e educação.
} 
os autores concebem as práticas discursivas como linguagem em ação. Mais especificamente, como "as maneiras a partir das quais as pessoas produzem sentidos e se posicionam em relações sociais cotidianas" (p. 45). Já por repertórios interpretativos, compreendem, com base na obra de Potter e Wetherell (1987),

[...] as unidades de construção das práticas discursivas - o conjunto de termos, descrições, lugares-comuns e figuras de linguagem que demarcam o rol de possibilidades de construçôes discursivas, tendo por parâmetros o contexto em que essas práticas são produzidas e os estilos gramaticais específicos ou speech genres (Spink \& Medrado, 1999, p. 47).

Essas unidades são, para os autores, fundamentais para o estudo das práticas discursivas, pois possibilitam a compreensão da variabilidade encontrada nas comunicações cotidianas, causada pela combinação contraditória de repertórios de discursos diversos. Nesta pesquisa, apresentamos a diversidade de repertórios empregados nas publicações e nas falas de membros do MVI para dar sentido à noção de vida independente. Para tanto, dividimos o texto em quatro tópicos: inicialmente, apresentamos e justificamos nossos procedimentos metodológicos (tópicos 1 e 2); em seguida, apresentamos as características gerais e uma breve história do Movimento no Brasil (tópico 3) e, por fim, apresentamos os principais repertórios interpretativos que seus ativistas usam para dar sentido à vida independente (tópico 4).

\section{A análise dos documentos de domínio público}

Para apreender os múltiplos sentidos que a literatura produzida pelo movimento social estudado imprime à expressão "vida independente", optamos por analisar publicações do MVI, pois, ao tomá-las como documentos de domínio público, ou seja, como produtos sociais tornados públicos, pensamos, com base nas reflexões de Peter Spink (1999), que elas têm grande potencial de circulação de sentidos e de reestruturação dos espaços institucionalizados de interação. Segundo o autor, como práticas discursivas, os documentos de domínio público podem assumir diversas formas, tais como diários oficiais, arquivos variados, jornais e revistas, anúncios, publicidade, manuais de instrução, relatórios anuais, etc. Neste estudo, analisamos jornais institucionais, manifestos, livros, livretos e sítios de internet.

Nosso acesso aos documentos de domínio público produzidos pelo MVI se deu, principalmente, por meio de indicações de membros do movimento, 
consultas a bancos virtuais de dados e visitas à biblioteca da Rede Saci³. Os principais bancos virtuais de dados que usamos foram os sítios dos Centros de Vida Independente (CVIs) brasileiros, ingleses e americanos, bem como do Independent Living Institute (organização sueca que oferece um grande número de documentos e artigos sobre vida independente e temas relacionados à deficiência). Além de textos eletrônicos, tivemos acesso a livros e periódicos impressos, a materiais publicitários, a documentos oficiais e a dissertações de mestrado sobre a militância de pessoas com deficiência. Entre todos os materiais consultados, selecionamos os que fariam parte do corpus desta pesquisa com base em três critérios: o contexto em que eles foram publicados, seus conteúdos e a filiação de seus autores ao MVI. Em relação ao primeiro critério, escolhemos somente os documentos divulgados em veículos de comunicação voltados para outros ativistas e, ou, simpatizantes da causa. Alguns dos textos analisados foram escritos por autores com formação acadêmica, mas foram publicados dentro de um contexto de militância (não seguindo nem os objetivos e nem as regras impostas pelo campo científico). Sendo assim, os consideramos como literatura do movimento e não como literatura acadêmica. Como encontramos uma grande quantidade de documentos que obedeciam a esse primeiro critério, selecionamos somente aqueles que discutiam questôes relacionadas à noção de vida independente e que haviam sido escritos por ativistas do MVI. Feito isso, demos início ao tratamento e análise dos dados.

Nesta etapa da investigação, buscamos primeiramente contextualizar nosso problema de pesquisa por meio da análise da história e da "filosofia" do Movimento. Em seguida, voltamo-nos para nossa questão central, buscando identificar, no material selecionado, os repertórios interpretativos relacionados à noção de vida independente. Para tanto, efetuamos inicialmente uma leitura completa dos sítios, artigos, livros e livretos selecionados, destacando os trechos relacionados ao nosso problema de pesquisa. A partir dessa leitura inicial, elaboramos quadros para cada um desses termos, nos quais a primeira coluna indicava a fonte, a segunda citava o trecho do texto onde o termo apareceu e a terceira apresentava notas sobre seu uso naquele contexto (tal como exemplificado no quadro 1). Em seguida, elaboramos um "glossário", ou seja, um quadro que apresenta sinteticamente os diferentes usos desses repertórios (quadro 2). Para isso, dedicamos a primeira coluna desse quadro

\footnotetext{
De acordo com as informações obtidas em seu sítio (www.saci.org.br), a Rede Saci é uma realização da Coordenadoria Executiva de Cooperação Universitária e de Atividades Especiais da Universidade de São Paulo (CECAE-USP), da Rede Nacional de Ensino e Pesquisa (RNP), do Amankay Instituto de Estudos e Pesquisa, e do Núcleo de Computação Eletrônica da Universidade Federal do Rio de Janeiro (NCE-UFRJ), e conta com o apoio da Fundação Telefônica e da Vitae. A Rede Saci possui uma rica biblioteca voltada para temas relacionados à deficiência (no campus da USP, em São Paulo) e oferece, na internet, canais de comunicação para difusão de informações sobre o tema.
} 
para os repertórios. $\mathrm{Na}$ segunda, elencamos seus usos, apontando para as expressões que os englobam e os significam, bem como para os verbos que os acompanham. Na terceira, apresentamos suas definições.

Com a produção desse glossário e também dos quadros de análise, buscamos mapear os documentos selecionados. E, com isso, identificar a multiplicidade de sentidos e repertórios interpretativos relacionados à vida independente. Além desse material, como já dissemos, também analisamos dois grupos focais realizados com alguns membros do MVI. Os procedimentos e justificativas desta etapa serão apresentados no tópico subsequente.

\section{Procedimentos metodológicos de análise dos grupos focais}

A escolha por esse tipo de corpus justifica-se, pois, como os grupos focais são bastante dialógicos, eles constituem um importante instrumento para a compreensão do processo de construção dos sentidos de vida independente. Segundo Carlini-Cotrin (1996), os grupos focais permitem que o pesquisador identifique não somente os sentidos que os participantes atribuem ao assunto estudado, mas também o processo de construção desses sentidos. Além disso, em comparação com outras técnicas de coleta de dados, os grupos focais permitem um caldo discursivo mais abrangente, resultando numa maior mobilidade das interações verbais, tornando-as mais próximas daquelas que ocorrem em situações cotidianas.

Partindo desses pressupostos, realizamos dois grupos focais com ativistas de um CVI paulista, o CVI Araci Nallin (CVI AN). O primeiro grupo focal (GF1) foi realizado na casa de uma das participantes, no dia 30 de setembro de 2006, e tinha como objetivo principal fornecer dados que nos permitissem conhecer melhor a história e as bandeiras do movimento brasileiro de pessoas com deficiência. Seis pessoas participaram desse grupo, sendo todas mulheres com deficiências físicas. Essa homogeneidade do grupo não foi intencional, já que convidamos ativistas com e sem deficiência, de ambos os sexos. $\mathrm{O}$ segundo grupo (GF2), por sua vez, foi realizado na casa de outra participante, em $1^{\circ}$ de abril de 2007, e voltou-se para a discussão acerca dos princípios de vida independente, seus principais conceitos e estratégias de luta. Quatro pessoas que haviam participado do primeiro grupo participaram também do segundo, sendo que este contou ainda com a colaboração de mais dois ativistas: a então presidente do CVI AN e o marido (único participante do sexo masculino e que não tinha deficiência).

Antes de apresentarmos os resultados que a análise desses grupos e dos documentos de domínio público nos proporcionou, consideramos importante 
apresentarmos uma breve história do MVI brasileiro, bem como suas principais bandeiras e estratégias de intervenção, já que "trabalhar no nível da produção de sentidos implica retomar também a linha da história, de modo a entender a construção social dos conceitos que utilizamos no métier cotidiano de dar sentido ao mundo" (Spink \& Medrado, 1999, p. 49).

\section{O Movimento de Vida Independente no Brasil}

A "filosofia" que embasa o MVI foi trazida para o Brasil no final da década de 1980, entretanto ela já existia em diversos países. Segundo Sassaki (2003), ela teve início em Berkeley (Califórnia), quando, na década de 1960, um grupo de estudantes com deficiências severas começou a reivindicar serviços que propiciassem uma vida mais independente e mais autônoma. De acordo com o sítio do CVI Berkeley (www.cilberkeley.org), em 1972, esses estudantes, juntamente com outras pessoas da comunidade que compartilhavam de seus ideais, fundaram oficialmente o primeiro Centro de Vida Independente do mundo. Dezesseis anos mais tarde, um grupo de ativistas com deficiência provenientes dos movimentos de base criou, no Rio de Janeiro, o primeiro CVI brasileiro. Seu principal objetivo era disseminar e estabelecer um novo modelo de organização, adaptando a filosofia e os serviços dos CVIs do "primeiro mundo" à realidade brasileira (Alonso, 2003).

A ampla aceitação da "filosofia" de vida independente, bem como a grande demanda por serviços voltados para pessoas com deficiência, fez com que logo fossem criados outros CVIs no País. Segundo o sítio do CVI Maringá (www.cvi-maringa.org.br), hoje existem 24 Centros de Vida Independente localizados em diferentes estados brasileiros e um Conselho Nacional, chamado CVI Brasil. Suas atividades são sempre lideradas e dirigidas por pessoas com deficiência, embora aqueles que não têm deficiência também possam atuar como colaboradores do movimento. Os CVIs são organizaçôes não governamentais, sem fins lucrativos, que têm como objetivo principal promover uma vida independente, produtiva, plena e de melhor qualidade para as pessoas com deficiência.

Os ativistas que trouxeram os primeiros CVIs para o País compartilhavam dos mesmos princípios que outros grupos reivindicativos dos direitos das pessoas com deficiência. Entretanto, enfatizavam a noção de vida independente e apresentavam estratégias de luta diferentes. Os ativistas dos outros grupos reivindicativos buscavam a inclusão, a equiparação de oportunidades e a conscientização social por meio de um trabalho voluntário de militância política. Já os do Movimento de Vida Independente, além de reivindicarem 
direitos e promoverem conscientização, ofereciam às pessoas com deficiência serviços, diretos ou indiretos, que as auxiliavam a se tornar instrumentos de sua própria emancipação social.

Essa capacitação se dava (e ainda hoje se dá) principalmente por meio de aconselhamento de pares; fornecimento de informações sobre deficiência, recursos comunitários etc.; defesa de direitos; assistência habitacional (especialmente sobre acessibilidade arquitetônica); provisão de transporte adaptado e de atendentes pessoais, organização de grupos de apoio; oferta de oportunidades de lazer e desenvolvimento pessoal; assistência profissional sobre alternativas de emprego; educação, conscientização, sensibilização da sociedade a respeito das necessidades e potencialidades das pessoas com deficiência e pesquisa de produtos de tecnologia assistiva (Sassaki, 2004). Todos esses serviços visam a transformar a "filosofia" de vida independente em prática de vida independente.

\section{A noção de vida independente e seus repertórios}

Uma primeira observação acerca desse conceito é que ele é polissêmico, isto é, assume uma diversidade grande de sentidos: ora é significado como filosofia, ora como movimento, ora como processo, ora como estilo de vida, etc. A nosso ver, esses múltiplos sentidos dificultam sua compreensão mais imediata, uma vez que podem levar o leitor mais desatento a crer que ele é empregado indiscriminadamente. Entretanto, uma análise mais cuidadosa dos discursos do Movimento nos indica que o fato de ele carregar generosa quantidade de sentidos é decorrência de ser compreendido, antes de tudo, como práxis. Assim, não há filosofia sem as diversas formas de vivenciar vida independente e vice-versa, fazendo com que teoria e prática constituam um todo ontológico.

Além de ter sempre em mente essa ideia de práxis, para compreendermos os sentidos que os ativistas do MVI atribuem à vida independente, é preciso compreender os repertórios que eles usam nesse processo de atribuição de sentidos. Em outras palavras, é preciso compreender o que eles chamam de independência, autonomia, empoderamento, autodeterminação, participação e igualdade de oportunidades.

\section{- Independência}

No livro El Movimiento deVida Independiente: experiencias internacionales (Alonso, 2003), ativistas de diversos países definiram independência como aquilo que indica que algo ou alguém deixou de depender de outros. $\mathrm{Ou}$ 
seja, para esses ativistas, independência indica soberania e controle de seu próprio destino, de seus pensamentos, de suas crenças religiosas, de suas opções políticas, de suas ações. Indica a não dependência em relação a uma autoridade institucional ou familiar. Nas palavras de Sassaki (2006, p. 35) ativista do CVI Araci Nallin - indica a "[...] faculdade de decidir sem depender de outras pessoas, tais como: membros da família, profissionais especializados ou professores".

Durante o GF2, uma das participantes definiu independência de forma similar a Sassaki (2006). Para ela, independência é a "possibilidade de uma pessoa escolher seus próprios caminhos". Em seguida, outra participante complementou, dizendo que é "a possibilidade de alguém tomar as próprias decisões". Para exemplificar uma situação em que uma pessoa exerce sua independência, a primeira relatou que

[...] Então, na prática, é assim: eu agora quero tomar guaraná, então eu vou lá e tomo guaraná. Eu não quero guaraná, eu quero Coca-Cola. Eu tô escolhendo. Pode ser que a Coca Cola me dê a maior dor de estômago. Problema é meu, sou eu que vou tomar remédio depois.

A partir desse depoimento, podemos dizer que, para essa ativista, ter independência implica assumir responsabilidades. Se ela decide tomar uma Coca-Cola, é ela quem deve refletir sobre a pertinência dessa escolha e, caso sua decisão resulte em problemas estomacais, é ela quem sofrerá as consequências. O importante nesse exemplo é que ela tem a oportunidade de escolher, ou seja, tem a oportunidade de exercer sua independência.

Segundo a ativista, além de responsabilidades, a independência implica, também, negociação. Em suas palavras,

Eu digo assim: "hoje eu quero almoçar fora, eu não vou cozinhar". E o Eduardo fala: "nós não vamos". Então a gente entra em um conflito normal, até chegar a um consenso. A gente resolve que vai pedir um McDonald's. Então, isso é independência. Não adianta você fazer o que você quer. É o que você quer desde um contexto social, né? E todo contexto social requer uma negociação. Por que são relaçõos interpessoais.

Nessa fala, a participante enfatiza o contexto social no qual estamos inseridos, indicando a nós que viver com independência não significa tomar decisões sem levar em conta a opinião de terceiros. Mas, sim, poder participar das tomadas de decisão. E, caso uma pessoa faça opções contrárias às de seus familiares e amigos, ela pode negociar, argumentar, tentar convencê-los de 
que sua opinião é a mais pertinente. Sendo assim, independência, para essa ativista, não significa isolamento ou término das relações interpessoais, mas, sim, a possibilidade de alguém participar em iguais condições das decisões que afetam sua vida.

Segundo Sassaki (2006), a possibilidade de alguém ser independente e tornar-se protagonista da própria história depende não somente da quantidade e da qualidade das informações disponíveis para tomar a decisão mais apropriada, mas também da autodeterminação e, ou, prontidão para tomar decisões numa dada situação. É importante ressaltarmos que, para o autor ativista, a autodeterminação e a prontidão para tomar decisões podem ser desenvolvidas e aprendidas. Prova disso é que, em seus textos, bem como nos outros analisados, a palavra independência geralmente vem acompanhada dos verbos construir, criar e conquistar. Todos eles se referem às habilidades para as quais grande parte dos serviços de vida independente está voltada.

A noção de independência está intimamente relacionada à de autonomia. Entretanto elas não são sinônimas. A seguir, buscaremos apresentar os sentidos que ativistas do MVI atribuem à autonomia, bem como discutir em que medida ela se aproxima ou se distancia da noção de independência.

\section{- Autonomia}

Esta inter-relação entre as noções de autonomia e independência pode ser comprovada pelo fato de, na maioria dos documentos de domínio público analisados, o vocábulo "autonomia" aparecer sempre seguido ou precedido pela palavra "independência". Em alguns textos, como os escritos por Sassaki (1995, 2004, 2006), esses termos se referem a conceitos distintos, porém, muitas vezes, complementares. Em outros, como os do sítio do CVI Maringá (www.cvi-maringa.org.br) e de Alonso (2003), a singularidade de cada um é menos evidente.

De acordo com Sassaki (2006, p. 35), a noção de autonomia refere-se à "[...] condição de domínio sobre o ambiente físico e social, preservando ao máximo a privacidade e a dignidade da pessoa que a exerce". Ou seja, dizer que uma pessoa tem maior ou menor grau de autonomia significa dizer que ela tem maior ou menor controle sobre os diversos ambientes físicos e sociais que ela queira e, ou, precise frequentar para atingir seus objetivos. Calçadas com rampas, prédios acessíveis e ônibus adaptados, por exemplo, permitem que pessoas com deficiência física se locomovam de uma maneira mais autônoma, ou seja, permitem que elas controlem seu ambiente físico sem precisar da ajuda de terceiros. 
Uma das participantes do GF2 definiu autonomia de uma forma bastante semelhante a Sassaki (2006). Para ela, esse conceito refere-se à capacidade de realizar atividades como, por exemplo, escovar os dentes, vestir-se, alimentarse, cozinhar, limpar a casa, etc., sem a ajuda de outras pessoas. Segundo a ativista, aqueles que apresentam deficiências bastante severas podem ter pouca autonomia para realizar atividades cotidianas, entretanto, isso não significa que eles não possam ser independentes. Como exemplo dessa relação, ela citou os casos de pessoas que têm comprometimento motor significativo e não têm autonomia para escovar os dentes sozinhas, mas que têm independência, pois escolhem o horário em que fazem sua higiene bucal, o creme dental que utilizam, etc. De acordo com a ativista, essas pessoas têm um grau de autonomia baixo, entretanto vivem sua independência em um nível bastante alto.

De acordo com Sassaki (2006), o grau de autonomia de uma pessoa não é algo estático, dado a priori, mas sim o resultado da relação entre o nível de prontidão físico-social da pessoa com deficiência e a realidade de um determinado ambiente. Assim, uma pessoa pode ser autônoma para descer de um ônibus ou atravessar uma rua sem ajuda de ninguém, enquanto outra precisaria de auxílio para transpor os obstáculos desse espaço. Entretanto, não podemos dizer que a primeira seja mais autônoma do que a segunda, ela o é nesse ambiente, que oferece essas condições. E como tanto o ambiente quanto a prontidão físico-social podem ser modificados, o grau de autonomia de uma pessoa também pode variar. E diversos fatores contribuem para isso: a pessoa pode desenvolver novas habilidades, adquirir equipamentos mais eficazes para executar uma tarefa ou o ambiente pode sofrer adaptaçôes.

Além de Sassaki, vários outros autores-ativistas referem-se à noção de autonomia. Na maioria dos textos analisados - como, por exemplo, Silva (2007) e os sítios dos CVIs Maringá, Araci Nallin e Campinas -, o termo aparece como um dos objetivos principais do Movimento de Vida Independente. Aparece como uma meta a ser atingida; um direito a ser conquistado por meio dos serviços oferecidos pelos CVIs; uma condição necessária para o empoderamento das pessoas com deficiência.

\section{- Empoderamento}

Segundo Sassaki, esse termo refere-se ao "[...] processo pelo qual uma pessoa, ou um grupo de pessoas, usa seu poder pessoal inerente à sua condição - por exemplo: deficiência, gênero, idade, cor - para fazer escolhas e tomar decisões, assumindo assim o controle de sua vida" (Sassaki, 2004, p. 11). Para o autor ativista, esse poder não pode ser outorgado às pessoas, já que está em 
cada ser humano desde o nascimento. Entretanto, é preciso aprender a usá-lo. Não é por menos que ele constantemente fala em "incentivar" e "conduzir" ao empoderamento.

Talvez o fato de referir-se a algo que pertence à pessoa desde seu nascimento seja a principal característica que distingue a noção de "empoderamento", tal como é definida por Sassaki (2004, 2006), da noção de "independência". Entretanto, o autor ativista não deixa claro se esse é, de fato, o único ponto divergente entre os dois conceitos, nem explicita o sentido da expressão "poder pessoal". Ele afirma somente que "[...] independência e empoderamento são conceitos interdependentes" (Sassaki, 2004, p. 11), não explicando como se dá relação entre eles.

Essa confusão fica bastante evidente quando o autor ativista afirma que, frequentemente, a sociedade (famílias, profissionais, instituições, etc.) "[...] não tem consciência de que a pessoa com deficiência também possui esse poder pessoal [...] e, em consequência, essa mesma sociedade faz escolhas e toma decisões por ela, acabando por assumir o controle da vida dela" (2006, p. 37). Nessa sentença, "poder pessoal" assume o mesmo sentido de "independência”. São conceitos diversos com significados análogos.

Os ativistas paulistanos igualmente usam, em seu site, o termo empoderamento com um sentido bastante similar ao de independência. Os campineiros, por sua vez, afirmam que o empoderamento estimula as potencialidades das pessoas com deficiência e possibilita a conquista de sua autonomia. Em seu sítio, eles defendem que

[...] é até natural que, em função da desestruturação emocional que sofre uma pessoa quando ela adquire uma deficiência, exista uma proteção maior por parte da família e dos profissionais que trabalham junto com essa pessoa. É exatamente por isso que um dos objetivos fundamentais do MVI é estimular a potencialidade de cada uma das pessoas com deficiência, de forma a fortalecê-la para fazer essas escolhas necessárias à sua vida. Os CVIs atuam como facilitadores desse processo, através de serviços de aconselhamento, assessorias, informaçôes, entre outros, trabalhando para que o brilho interior, que existe em cada um de nós, floresça e seja despertado, possibilitando que a pessoa com deficiência conquiste sua autonomia. $\mathrm{O}$ termo em inglês que exprime esse processo é empowerment, em português, "empoderamento" (Centro de Vida Independente de Campinas, 2007).

A partir dessa definição proposta pelo CVI Campinas, podemos dizer que, para esses ativistas, o vocábulo "empoderamento" refere-se ao processo 
de aquisição do poder pessoal de fazer escolhas e tomar decisões sobre os diferentes aspectos da vida, sendo que é esse poder que permite que pessoas com deficiência participem ativamente da sociedade e que sejam reconhecidas como cidadãs plenas.

Podemos dizer, então, que o repertório "empoderamento" é significado de diferentes formas pelos ativistas do MVI: ora é sinônimo de independência; ora é o potencial de tornar-se independente e ora é o processo de aquisição de independência, autonomia e autodeterminação.

\section{- Autodeterminação}

Embora não tenha sido citada durante os grupos focais, autodeterminação é uma expressão bastante usada em um dos documentos de domínio público analisados para se referir à possibilidade de alguém escolher os próprios caminhos. Segundo Alonso, o princípio de autodeterminação "[...] supõe uma clara mudança de visão e de enfoque, que reforça o caráter impessoal e social da deficiência. A autodeterminação supõe a assimilação do poder de controle e decisão pela própria pessoa" (Alonso, 2003, p. 43, tradução nossa). Nessa perspectiva, o MVI funciona como um "[...] veículo de ideias que contribuem para fortalecer os direitos que pertencem somente ao indivíduo, os mesmos que reportam à autodeterminação e à liberdade para governar cada um e todos os aspectos de sua vida frente a qualquer dependência possível" (Alonso, 2003, p. 270-271, tradução nossa).

A partir dessas duas citações, podemos dizer que, para Alonso, a noção de autodeterminação está intimamente relacionada à de independência. A primeira é definida como "poder de controle e decisão pela própria pessoa" (Alonso, 2003, p. 43, tradução nossa) e a segunda como "controle máximo de suas vidas, baseado na capacidade e na oportunidade de tomar decisões e de levar a cabo as atividades do dia a dia" (Alonso, 2003, p. 151, tradução nossa). Por outro lado, a noção de autodeterminação relaciona-se, também, com a de autocontrole. Afinal, para o autor ativista, ela diz respeito ao poder de controle e decisão das pessoas com deficiência.

\section{- Participação e igualdade de oportunidades}

Outro repertório que dá sentido à noção de vida independente é "participação". Nos documentos de domínio público que analisamos, essa palavra é usada para referir-se tanto à participação de pessoas com deficiência em processos decisórios quanto à sua participação na sociedade como um todo. Ao falar de participação social, os autores ativistas, frequentemente, usam o 
adjetivo "plena”. Com isso, parecem enfatizar que essa participação deve abranger todos os setores da sociedade, tais como mercado de trabalho, educação, lazer, cultura, política, etc. Além disso, eles apontam para a relação entre a noção de participação e a de igualdade (ou equiparação) de oportunidades. O que eles defendem é que, para que pessoas com deficiência participem plenamente da sociedade, é preciso que tenham os mesmos direitos e oportunidades que os cidadãos "comuns". Ou seja, é preciso que possam estudar, trabalhar, deslocar-se para os lugares queiram e, ou, precisem ir, etc.

Para que haja igualdade de oportunidades, é preciso também que pessoas com deficiência participem de processos decisórios e de elaboração das políticas públicas de seu interesse. Mas, a despeito de ser fundamental, a oportunidade de participar de processos legislativos e políticos não é suficiente. É preciso que as pessoas com deficiência participem de todos os setores da sociedade, inclusive dos serviços de vida independente dos quais usufruem. No sítio do CVI Rio (www.cvi-rio.org.br), esse papel ativo de seus usuários está bastante enfatizado: de acordo com seus ativistas, "o CVI Rio direciona-se para um modelo inovador de prestação de serviços e de resgate da cidadania na área da deficiência, onde a própria pessoa com deficiência é agente ativo do processo de que participa, assumindo seus desejos, escolhas e decisões”.

É importante ressaltarmos que, ao falar em participação nos serviços de Vida Independente ou em participação na elaboração de políticas públicas, os autores-ativistas tratam, a nosso ver, também do tema "independência". Isso decorre do fato de que, para nós, somente pessoas capazes de fazer escolhas e tomar decisões sobre os diferentes aspectos que afetam sua vida podem participar ativamente desses processos.

Um dos serviços de vida independente que ajuda não somente a aumentar a participação das pessoas com deficiência, mas também a transformar as noções de independência, autonomia, empoderamento e autodeterminação em práticas cotidianas, é o aconselhamento de pares. Segundo Alonso e colaboradores (2003), nesse serviço, pessoas com deficiência que têm experiência em alcançar seus objetivos pessoais assessoram seus pares sobre a melhor maneira de proceder para ter um estilo de vida independente. Além de oferecer informações técnicas sobre direitos, eliminação de barreiras arquitetônicas, etc., os "conselheiros" oferecem apoio afetivo àqueles que necessitam. Segundo uma das participantes do GF2, no aconselhamento de pares, uma pessoa com deficiência mais "experiente" serve de exemplo para uma "novata", entretanto 
[...] não é aquela coisa de você chegar lá e dizer "Ó, você não vai andar mais, então você tem que fazer isso, fazer aquilo, fazer aquilo..." Acho que não é por aí, né? Eu acho que é você fazer com que a pessoa chegue a um nível onde ela mesma vai chegar a essa conclusão [...] Não que ela vá dizer "olha sou o exemplo, mire-se em mim". Mas ela vai ser a personificação da possibilidade que aquela pessoa tem de também retomar a sua vida nos níveis que ela tinha antes, apesar da deficiência. Então, eu acho que é um pouco por aí que o CVI funciona. [...] E isso, sem que a pessoa vá lá pra dar nenhum tipo de lição de moral... nenhum tipo de lição de vida, né? Mas elas, essas pessoas são uma prova de que existe essa possibilidade. $\mathrm{E}$, às vezes, é só isso que a pessoa precisa: ter a ideia de que existe essa outra possibilidade, de que a vida não acabou. Não é porque se tornou deficiente, que a vida acabou. Então é por aí...

Com base nesse depoimento, podemos dizer que, a despeito de se chamar "aconselhamento", esse serviço está longe de ser um espaço em que pessoas com mais experiência na área da deficiência dão conselhos e dizem o que os "novatos" devem ou não fazer. Mesmo porque isso seria incoerente com a proposta do movimento. Antes de ser um "aconselhamento" propriamente dito, esse serviço constitui uma possibilidade de trocar experiências e de mostrar, na prática, que pessoas com deficiência, apesar de suas limitações, têm também habilidades e podem trabalhar, estudar, namorar, casar. Ou seja, o aconselhamento de pares mostra que elas também podem viver uma vida independente.

\section{Considerações finais}

Os resultados que obtivemos por meio da análise dos documentos de domínio público e dos grupos focais nos permitem dizer que os ativistas do MVI fazem uso de diferentes repertórios para dar sentido à vida independente, tais como independência, autonomia, empoderamento, autodeterminação, participação e igualdade de oportunidades. Muitas vezes não há uma distinção clara entre essas noções, e nem sempre há consenso acerca de seus significados. Entretanto não consideramos que essa imprecisão conceitual seja uma limitação ou uma falha do Movimento. Pelo contrário, a contradição, a fluidez e a variabilidade de significados são características inerentes à noção de repertórios interpretativos. Segundo M. J. Spink e Medrado (1999, p. 48),

[...] esse conceito é particularmente útil para entendermos

a variabilidade usualmente encontrada nas comunicações cotidianas, quando repertórios próprios de discursos diversos são 
combinados de formas pouco usuais, obedecendo a uma linha de argumentação, mas gerando, frequentemente, contradições. $\mathrm{O}$ foco dos estudos que adotam esse conceito deixa de ser, assim, apenas a regularidade, o invariável, o consenso e passa a incluir também a própria variabilidade e polissemia que caracterizam os discursos.

Ou seja, passa a incluir a propriedade que uma palavra tem de, em um momento histórico determinado, representar diferentes ideias, estas oriundas de diferentes contextos, situações ou gêneros de fala.

Neste trabalho, não objetivamos buscar a origem de cada um dos repertórios analisados, mas sim mostrar a variabilidade de termos e ideias que a noção de vida independente evoca. Entretanto, podemos levantar algumas hipóteses: talvez o uso da palavra "autodeterminação" esteja relacionado a alguma singularidade da língua ou da cultura espanhola, uma vez que foi usada somente no livro coordenado por Alonso (2003) - escrito originalmente em espanhol -, sendo que, no Brasil, a palavra mais usada para referir-se à "possibilidade de alguém escolher seus próprios caminhos” seria independência. Ou ainda, poderíamos dizer que algumas das definições propostas pelos ativistas, principalmente por Sassaki (2003, 2004, 2006), representam uma tentativa de incorporar conceitos acadêmicos à "filosofia" do Movimento. Tentativa que, muitas vezes, acabaria "adaptando" - como o próprio autor diz (Sassaki, 2004) - esses conceitos à proposta do MVI, ou seja, acabaria modificando as definições originais a fim de não as tornar incoerentes com o nome ou com a "filosofia" do Movimento. Mas essas são apenas hipóteses engendradas por nossas análises, que merecem ser mais bem abordadas em estudos posteriores.

A despeito dessas imprecisões e contradições, podemos concluir que os repertórios analisados contribuem para colocar em prática uma nova forma de compreender a deficiência. Por meio de seu uso, temos indicativos de que os ativistas do MVI buscam ser reconhecidos como atores sociais, participar ativamente da sociedade e assumir o controle de suas vidas. Eles acreditam que isso é possível somente por meio da conquista da autonomia pessoal e da vida independente. $\mathrm{Ou}$ seja, que isso é possível somente quando as pessoas com deficiência passam a ser protagonistas de suas vidas, passam a ser cidadãs plenas, desinstitucionalizadas, que se ajudam mutuamente e que confrontam o sistema social, sanitário e institucional que as colocam na condição de desviantes. 


\section{Referências}

Alonso, J. G. V. (coord.). (2003). El movimiento de vida independiente: experiencias internacionales. Madrid: Fundación Luis Vives.

Amaral, L. A. (1996). Deficiência: questôes conceituais e alguns de seus desdobramentos. Cadernos de Psicologia, 1 (1), 3-12.

Carlini-Cotrim, B. (1996). Potencialidades da técnica grupo focal em investigações sobre abuso de substâncias. Revista Saúde Pública, 3 (30), 285293.

Center for Independent Living. (2007) History of CIL. Berkeley. Disponível em: <http://www. cilberkeley.org/history.htm>. (Acesso em: 14 mar. 2007).

Centro de Vida Independente Araci Nallin. (2007) Centro de Vida Independente Araci Nallin. Disponível em: <cvian.sites.uol.com.br>. (Acesso em: 20 fev. 2007).

Centro de Vida Independente Araci Nallin. (2007). Vida Independente: conceito. Disponível em: <http://www.cvi.org.br/vidaindependente.asp>. (Acesso em: 20 fev. 2007).

Centro de Vida Independente de Campinas. (2007). CVI Campinas. Disponível em: <http://www.cvicampinas.com.br/>. (Acesso em: 20 maio 2007).

Centro de Vida Independente de Maringá (2007). Maringá: Centro de Vida Independente. Disponível em: <http://www.cvi-maringa.org.br/>. (Acesso em: 20 maio 2007).

Centro de Vida Independente do Rio de Janeiro. (2006). CVI Rio: sua limitação não é seu limite. Disponível em: <http://www.cvi-rio.org.br/>. Acesso em: 22 jul. 2006.

Independent Living Institute. (2007). The www.independentliving. org Library. Disponível em: <http://www.independentliving.org/library.html>. (Acesso em: 20 maio 2007).

Neves, T. R. L. (2000). Movimentos sociais, autoadvocacia e educação para a cidadania de pessoas com deficiência mental. Dissertação de mestrado, Programa de Pós-graduação em Educação Especial, Universidade Federal de São Carlos, São Carlos. 
Nunes, L. R. D. P.; Glat, R.; Ferreira, J. R. \& Mendes, E. G. (1998). Pesquisa em educação especial na pós-graduação. Rio de Janeiro: Viveiros de Castro.

Potter, J., \& Wetherell, M. (1987). Discourse and social psychology: beyond attitudes and behavior. London: Sage Publications.

Rede Saci. (2007). O que é a Rede Saci. Disponível em: <http://www.saci.org. br/?IZUMI_SECAO=2>. (Acesso em : 20 mar. 2007).

Sassaki, R. K. (2003). Vida independente: história, movimento, liderança, conceito, filosofia e fundamentos. Reabilitação, emprego e terminologias. São Paulo: RNR.

Sassaki, R. K. (2004). Vida independente: na era da sociedade inclusiva. São Paulo: RNR.

Sassaki, R. K. (2006). Os novos paradigmas. In: R. K. Sassaki. Inclusão: construindo uma sociedade para todos (7. ed.). Rio de Janeiro: WVA.

Sassaki, R. K.(1995). Serviços de vida independente e conceito de vida independente. São Paulo: Prodef.

Silva, M. I. (2007, janeiro/fevereiro). Conheça o Centro de Vida Independente e a criação dos CVIs. Jornal da Associação dos Amigos Metroviários dos Excepcionai, p. 3.

Spink, M. J. \& Medrado, B. (1999). Produção de sentidos no cotidiano: uma abordagem teórico-metodológica para análise das práticas discursivas. In: M. J. Spink. (org.). Práticas discursivas e produção de sentidos no cotidiano. (p. 4162). São Paulo: Cortez.

Spink, P. (1999). Análise de documentos de domínio público. In: M. J. Spink. (org.). Práticas discursivas e produção de sentidos no cotidiano. (p. 123-152). São Paulo: Cortez, 